\title{
Vincent DURAND-DASTES, La Conversion de l'Orient. Une pérégrination didactique de Bodhidharma dans un roman chinois du XVII ${ }^{\mathrm{e}}$ siècle
}

Bruxelles, Institut belge des hautes études chinoises, coll. «Mélanges chinois et bouddhiques», 29, 2008, ix + 437 p.

Françoise Aubin

\section{(2) OpenEdition}

Édition électronique

URL : http://journals.openedition.org/assr/22600

DOI : $10.4000 /$ assr.22600

ISSN : $1777-5825$

Éditeur

Éditions de l'EHESS

\section{Édition imprimée}

Date de publication : 31 décembre 2010

Pagination : 9-242

ISBN : 9782713223013

ISSN : 0335-5985

Référence électronique

Françoise Aubin, «Vincent DuRAND-DASTEs, La Conversion de l'Orient. Une pérégrination didactique de Bodhidharma dans un roman chinois du xvII e siècle », Archives de sciences sociales des religions [En ligne], 152 | octobre-décembre 2010, document 152-46, mis en ligne le 12 mai 2011, consulté le 21 septembre 2020. URL : http://journals.openedition.org/assr/22600 ; DOI : https://doi.org/10.4000/ assr.22600

Ce document a été généré automatiquement le 21 septembre 2020.

(C) Archives de sciences sociales des religions 


\section{Vincent DURAND-DASTES, La}

Conversion de l'Orient. Une pérégrination didactique de Bodhidharma dans un roman

\section{chinois du XVII ${ }^{\mathrm{e}}$ siècle}

Bruxelles, Institut belge des hautes études chinoises, coll. «Mélanges

chinois et bouddhiques», 29, 2008, ix + $437 \mathrm{p}$.

Françoise Aubin

\section{RÉFÉRENCE}

Vincent DURAND-DASTES, La Conversion de l'Orient. Une pérégrination didactique de Bodhidharma dans un roman chinois du XvII ${ }^{e}$ siècle, Bruxelles, Institut belge des hautes études chinoises, coll. «Mélanges chinois et bouddhiques», 29, 2008, ix + $437 \mathrm{p}$.

1 Quel plaisir d'avoir à rendre compte d'un ouvrage aussi distrayant que savant et instructif! Le titre principal laisserait pourtant attendre une étude sévère de contacts interreligieux. De fait, il s'agit d'un palpitant roman populaire, en langue vulgaire et à épisodes multiples, sur fond de moralisme confucéen, le Saomei dunlun Dongdu ji «L'éviction des démons et la restauration des bonnes relations sociales, ou la Conversion de l'Orient» (en abrégé Dongdu ji), paru dans les dernières années des Ming, en 1635 .

2 Le premier intérêt de cette histoire réside en son héros: un moine indien légendaire, Bodhidharma, censé avoir apporté en Chine le bouddhisme zen (selon le terme japonais le plus usuel chez nous, en chinois chan) dans les premières décennies $\mathrm{du} \mathrm{VI}^{\mathrm{e}}$ siècle de notre ère. La littérature bouddhique en langue classique chinoise le représente comme un personnage clef à la charnière d'une lignée de vingt-sept patriarches indiens 
remontant au Bouddha historique et d'une longue lignée chinoise se réclamant de son enseignement. Au cours des siècles, son hagiographie se développe; puis elle se mue, vers le $\mathrm{XVI}^{\mathrm{e}}$ siècle, sous les Ming, en une littérature narrative en langue vulgaire, qui mélange théologie, merveilleux et violence. C'est à ce genre qu'appartient l'ouvrage ici analysé (chap.1).

3 L'arrière-plan idéologique qui l'anime est celui à la mode en ce temps: la conviction d'une unité ou fusion des trois enseignements, confucianisme, bouddhisme et taoïsme (la théorie dite du sanjiao heyi). Son thème principal est une allégorie du progrès moral atteint grâce à la restauration des cinq «relations sociales cardinales», véritable panacée aux maux du siècle vantée par le néoconfucianisme. Mais une stricte hiérarchie doit être maintenue, les classes dominées, femmes et serviteurs, étant potentiellement les plus dangereuses si elles ne sont pas bien tenues en laisse, comme le montrent plusieurs épisodes: pour la femme, il est recommandé qu'elle soit laide et pieuse et pour le pauvre, qu'il soit obstinément content de son sort. Si les marchands sont constamment critiqués, ils sont cependant valorisés comme pieux donateurs. Personnages et lieux sont allégoriques, notamment les opposants les plus durs à l'entreprise de conversion menée par le moine indien qui sont les «quatre vices» ivrognerie, luxure, lucre, colère - apparaissant sous de multiples figures démoniaques. Le comparatiste des religions ne manquera pas de relever incidemment que la culpabilisation généralisée n'est pas absente de l'éthique religieuse comme on le disait jadis dans les travaux de missiologie chrétienne exposant les difficultés de l'évangélisation en Chine (p.83, note 182). Et que le ciel, en ce roman, est vide et les êtres divins impersonnels (pp.116-117): en effet, le rachat des fautes résulte de la médiation, non des dieux, mais des moines bouddhistes (chap.2).

Car, dans ce roman si confucéen par les principes qu'il défend, les personnages positifs sont non pas des lettrés, mais des moines bouddhistes; en outre, des pointes sont envoyées occasionnellement contre les praticiens du taoïsme. La méditation, l'éveil, la valorisation de la spontanéité, le rejet des rites et des textes canoniques, le caractère sibyllin de l'enseignement oral de Bodhidharma, tout relève du modèle rhétorique chan. Et la condamnation bouddhiste de l'alimentation carnée fait des bêtes abattues pour la boucherie des "génies» (jing) destinés à tirer vengeance des carnivores et des meurtriers. L'originalité du présent roman est que les instincts vengeurs de ces esprits animaux se bonifient au contact des moines pour se transformer en outils salvateurs: intimidants pour le pécheur, ils ne commettent cependant aucun acte violent, laissant au message bouddhique son aura de douceur et de compassion. Finalement, la première des préoccupations du romancier est la détermination des aliments qu'on peut légitimement consommer (chap.3).

5 Ce roman, en répétant inlassablement les mêmes motifs moraux, relève, certes, de la littérature édifiante courante en son temps. Mais il le fait sous une forme très particulière: celle du roman en langue vulgaire, en une version longue de cent chapitres: le modèle en est l'illustre Pérégrination vers l'Ouest (le Xiyou ji, dont la plus ancienne édition connue en cent chapitres date de 1592). La Conversion de l'Orient apparaît comme une suite inversée, puisque la marche du héros civilisateur va d'Ouest en Est; les «quatre vices» y sont des démons pervers constamment engagés dans des joutes verbales. Mais l'évidence d'un second modèle concurrent s'impose aussi: le «Roman des trois enseignements» (le Sanjiao kaimi de Pan Jingruo, en cent chapitres aussi, publié sans doute en 1627), qui narre comment les défenseurs des «trois 
enseignements» résolvent les cas soulevés par les troubles de l'ordre social (chap.4). La tentative d'identification des éditeurs et des auteurs des romans ici cités que tente V.Durand-Dastes montre la complexité de cette question sous les Ming et les Qing. Et cela d'autant plus que le Roman des trois enseignements ayant été condamné dès sa parution, sa suite indirecte, la Conversion de l'Orient, se trouve à l'époque de Kangxi (1662-1723) rattachée par ses éditeurs à la Pérégrination vers l'ouest (chap.5; sur les éditions de l'époque de Kangxi, voir pp.350-356). L'ouvrage est ensuite plus ou moins oublié jusqu'à ce qu'au $\mathrm{xx}^{\mathrm{e}}$ siècle, les critiques littéraires le prennent à nouveau en compte. Mais les commentaires univoques qu'ils en donnent ne rendent pas compte du foisonnement de réponses que peut entraîner une lecture synchronique, à la fois historique et textuelle, comme celle à laquelle V.Durand-Dastes s'est livrée en conjuguant l'analyse interne du roman avec celle de son cadre intellectuel et de son milieu social (chap.6).

6 En conclusion à ce travail magistral, la figure littéraire de Bodhidharma est analysée: il apparaît qu'il n'est pas traité dans ce roman comme un héros épique à proprement parler, mais comme un pivot autour duquel évoluent les démons à combattre et comme le porte-parole de l'auteur-pédagogue. On le trouve ainsi, en cette fin des Ming, couramment utilisé dans les arts graphiques, les romans, les pièces de théâtre. Mais il ne va pas avoir de postérité littéraire, car l'instruction morale et religieuse va bientôt utiliser des modes d'expression plus sérieux que le roman en langue vulgaire: ce Bodhidharma profane ne peut plus convenir à la sensibilité des moralistes et des groupes religieux de l'époque Qing. La traduction de trois délicieux chapitres permet in fine au lecteur de goûter directement à l'inventivité du romancier chinois (pp.317-344). Tandis que soixante pages de bibliographie confirment le caractère érudit du travail de V.Durand-Dastes.

7 Mais dans quelle case théorique le classer? Il est certain qu'y trouveront matière à découvertes et à réflexion autant les historiens et comparatistes des religions et de la pensée didactique que les historiens de la littérature. Et pour tous un modèle d'une érudition impeccable et pourtant légère à porter. 